\title{
A 5-year school-based comprehensive preventive program in Michigan, U.S.A.
}

\author{
Robert A. BAGRAminn \\ Iniversity of Michigan, School of Dentistry, Ann Aibor, Michigan, U.S.A.
}

\begin{abstract}
Bagramian, R. A.: A 5-year school-based comprehensive preventive program in Michigan, U.S.A. Community Dent. Oral Epidemiol. 1982: 10: 234-237.

Abstract - The objectives were to demonstrate that a combination of preventive regimens could significantly reduce dental disease in a school population, to demonstrate the feasibility of a school-based program in relation to sustained benefits. There were 1286 students in 1 st and $61 \mathrm{~h}$ grades enrolled in the study. Subjects were stratified by grade, sex, and race and randomly placed in a treatment or education group. Procedures included ingestion of fluoridated water, oral hygienc education program, dental cxaminations, prophylaxis, acidulated phosphatefluoride gel $(1.23 \%)$ applied in trays, pit and lissure sealants (bis-GM $\Lambda$ ) on occlusal surfaces of all eligible posterior teeth, and provision of all restorative care. Fluoride and sealant procedures were repeated at 6 -month intervals. Alter 3 years the treatment group was mandomly divided to provide a group that would not continue with treatment and serve as a comparison. The study population was curolled in 18 schools and clinical procedures were provided on-site, using mobile dental vans. live-year results indicate high degree of success with fall-ofl ol benefits to those for whom treatment was terminated. This pilot program gives strong evidence for the possibility of implementing school-based dental programs. The study also indicates that prevention programs must be comprehensive and continuous for maximum benefit to occur.
\end{abstract}

Key words: dental caries; tissure sealants; lluorides.

Robert A. Bagramian, Department of Community Dentistry, University of Michigan School of Dentistry, Ann Arbor, MI 48109. U.S.A.

Accepted for publication 21 February 1982.

The increasing emphasis on attempts to prevent disease is particularly appropriate for dental diseases because of their extremely high prevalence and because dental caries and periodontal disease are largely preventable. Prevention has been emphasized recently and practical methods for reducing dental caries may be employed in the routine general practice of dentistry. Each of the individual preventive methods of water fluoridation (6), topical fluorides (7), health education (11), occlusal sealants (9), and restorative care (10) have been studied and reported singly and in some limited combinations. Few studies, however, have reported the combined effects of preventive methods that could be incorporated into routine dental practice to greatly reduce the problem of dental caries. The Askov dental project (8) conducted during the period from 1948 through 1958 was an early study to demonstrate the effectiveness of a combination of preventive procedures. This 10 year study investigated the combined caries-preventive benefits of several methods pract iced during that period which included the application of fluoride topically, supervised daily toothbrushing, dental health education, restriction of dietary carbohydrates and provision of restorative care. At the end of 10 years, the study showed reductions of $34 \%$ in DMF teeth in children aged $6-12$ years and $14 \%$ in children aged $13-17$ years. The children in the study, however, were not consuming fluoridated water and sealants were not available.

The study being reported here is unique in combining several preventive and therapeutic methods to significantly reduce dental caries. The 
use of mobile vans to provide services on-site and the opportunity after 3 years to subdivide the treatment group allows conclusions that could not otherwise have been made. Previous reports have described the project and presented interim results $(1-5)$.

\section{METHODS}

$A$ description of the project and population has been published (2). The original study population comprised 1286 children enrolled in Ist and 6th grades of 18 schools in the school districts of Ypsilanti and Willow Rum, Michigan. Onc-hall of this number was randomly assigned to the treatment group, the other half to the comparison groups.

Two screening appointments were scheduled in cach school year, an annual and a mid-year. At the mid-year screening, the treatment group shildren alone were examined to decermine sealant status. No radiograples were taken at this time. Children in the treatment group were provided with a combination of live preventive methods in the order listed below:

I. An oral hygiene program in classrooms includingsupervised toonhbrushing and llossing aided by disclosing tablets for 32 weeks in the year, and dictary comseling.

2. Dental examination followed by prophylaxis every 6 months.

3. Application of bis-GMA pit and fissure sealant (Nuraseal ${ }^{(R)}$. Buonocore Method) to the occlusal surtaces of eligible posterior teeth. Sealants lost were reapplied every 6 month.

4. Topical application of aciduated phosphate fuoride in a tray for 4 min every of months.

5. All necessary restorative cate.

Children from the comparison group necessarily consumed fluoridated water and, in addition, the oral hygiene program was also availabie to them.

Newly crupted teeth qualified for sealant application once the occlusal surface had penctrated the gingival tisste. At the amual screening children from boh groups were examined. Bitewing radiographs were also taken. For the treatment group, sealant examination was also done followed by the reatment procedures listed above.

The application of sealant was performed accotding to the method of Buonocone by a licensed dent ist working with dental assistants. All treatment procedures were conducted at school sites by the dentist and auxiliaries whiling mobile dental vans. The health colucation program was coordinated by a denal hygienist with a background in education.

Assessments at both examinat ions were conducted by dental epideniologists. Lxaminations were carted out under completely blind conditions. The oral condition of the mouth was judged by the number of DMF tecth and surfaces, and the calculus, debris, and periodontal index scores. Criteria used to assess dental caries were these developed at the $1968 \mathrm{ADA}$ Conference on the clinical testing of cariostatic agents (12).

At the end of 3 years the treatment group was randomly divided to provide a group that would not continue with treatment and serve as a comparison. After 5 years the conchusion of the study observed thec groups; the treatment group that received the complete program for 5 years, a treatment comparion group that received the complete program lor 3 years and discontinued for 2 years, and a comparison group that did not recive any weatment other than the oral hygiene program for 5 years.

\section{PARTICIPATION AND AGGEPTANCE}

$A$ total of 1286 students in the lst and fith grades volunteesed to participate in the study. This represented $85 \%$ of the students at the respective grade levels in atrendance at the elementary schools in the optimally [luoridated area serviced by the city of Spsilanti. Or this group, 698 were in the 1 st grade and 589 were in the bih grade when the study began. $A$ baseline sereening which inchuded bitewing radiographs was done for all the children. Aferwards, the entire group was stratified on the batsis of grade. sex and race. Each stratum was then shuflled and dealt out into two stacks, onte of which was subsequently arbitrarily labeled "treatment group" and the other "control group". Acljustments were then made to assure that children from the same lamily would not be in different groups. If one child in a lamily was in the treatment group, any other childeen from the same family were also placed in the treatment group. This resulted in a reatmem group of 6.30 students (349, Ist grade; 301, 6th grade) and a control group of $636(349$, Ist grade and 287 , 6th grade). Fifty-one perent of the students were still active participants in the study when it terminated after 5 years. This figure is derived from 3.33 in the treatment group (193. Ist grade group; 140, 6th grade group) plus 329 in the control group (I99, Ist grade group: 130, 6h grade group).

Subject loss averaged out to be $9.7 \%$ per year. Participation in the program was quite high when considering nomal attrition and other factors such as the initiation of a major auto union dental insurance plan during the study for most families in the program.

\section{COSTS}

Treatment lacilities for the study were two mobile dental sans equipped with two operatories each. The vans were purchased and fully equipped for a total cost of $\$ 75000$. The 5 -year cost of operating the 2 mobile vans was $\$ 13727$. This represents a facility cost of $\$ 18$ per year per student involved in the project. By including persomel and other costs, the total cost per student was $\$ 146.58$ per year. These figures do not account for the positive cflects in addition to caries reductions of the program being present in the school system. Areas that have not been measured but can be considered influential are inservice workshops for leachers, dental healuh education materials from the project utilized by other classes, peer pressure to improve oral health, and general increased mal healuh awareness as a result of dental activities surrounding this project. These ligures also do not rellect the reduction in costs that would occur over a longer period due in lower equipment costs since the mobile vans are still quite servicuable and were not amortized. 


\section{RESULTS}

Group 1 is the treatment group that received all procedures from the init iation of the project. Group 2 received all procedures for 3 years and then only annual exams similar to group 3 , the original comparison group. The mean DMFS increment from baseline to 5 th year for lst graders in treatment group 1 was 1.22 ; for the treatment/comparison group 2 it was 1.46 , and 2.28 for the comparison group. Corresponding figures for 6 th graders were $1.77,3.26$ and 4.46 (Tables 1 and 2). Treatment group 1 had the smallest increment

Table 1. Five-year DMFS increment in first grade children, Ypsilanti, Michigan 1973-1978

\begin{tabular}{|c|c|c|c|c|c|}
\hline \multirow[b]{2}{*}{ Gioup } & \multirow[b]{2}{*}{$n$} & \multicolumn{2}{|c|}{ Baselinc exam } & \multicolumn{2}{|c|}{$\begin{array}{l}\text { Increment from } \\
\text { bascline to lifth year }\end{array}$} \\
\hline & & Mean & s.d. & Mean & s.d. \\
\hline Treatment & 96 & 0.4896 & 1.2481 & 1.2188 & 1.6809 \\
\hline Trealment 2 & 97 & 0.2371 & 0.7184 & 1.4639 & 1.9314 \\
\hline Comparison & 199 & 0.3317 & 1.0252 & 2.2814 & 2.6745 \\
\hline
\end{tabular}

Table 2. Five-year DMFS increment in sixth grade children, Ypsilanti, Michigan, 1973-1978

\begin{tabular}{|c|c|c|c|c|c|}
\hline \multirow[b]{2}{*}{ Group } & \multirow[b]{2}{*}{$n$} & \multicolumn{2}{|c|}{ Baseline cxam } & \multicolumn{2}{|c|}{$\begin{array}{c}\text { Increment fiom } \\
\text { baseline to fiftl year }\end{array}$} \\
\hline & & Mean & s.d. & Mean & s.d. \\
\hline Treatment I & 78 & 4.7564 & 4.7130 & 1.7692 & 3.4488 \\
\hline Trealment 2 & 62 & 5.3065 & 4.2948 & 3.2581 & 3.9461 \\
\hline Comparison & 130 & 5.3308 & 4.7355 & 4.4615 & 4.8913 \\
\hline
\end{tabular}

followed by treatment group 2 and the highest increment for the comparison group. The difference in increment between the comparison group and each of the two treatment groups was statistically significant $(P<0.05)$. The analysis of the caries increment by surface type showed a significant difference in occlusal increment between each of the treatment groups 1 and 2 and the comparison group. Occlusal increment for 1 st grade children in group 1 was 0.75 ; for group 2 was 0.96 ; and for comparison was 1.38 (Table 3). Corresponding figures for 6th graders were $0.81,1.66$ and 2.29 (Table 4). All of the study children consumed fluoridated water which would make smooth surface reductions in all three groups similar. The mesiodistal increment, therefore, was essentially similar in all of the children. From a clinical standpoint, smooth surface increments for older children followed an interesting pattern. The lowest increment was for treatment group I followed by group 2 with the highest increment in the comparison group. This clinical difference could be attributed to the effect of topical fluoride applications.

The combined treatment procedures which were continued for treatment group 1 reduced the dental caries increment by $64 \%$ in older children and by $40 \%$ in younger children. The percent reductions in caries increment for children from treatment group 2 which had treatment discontinued after 3 years were not as high. The reduct ions were $29 \%$ for older. children and $24 \%$ for younger children. The oc-

Table 3. Five-year DMFS increment by surface type in first grade children, Ypsilanti, Michigan, 1973-1978

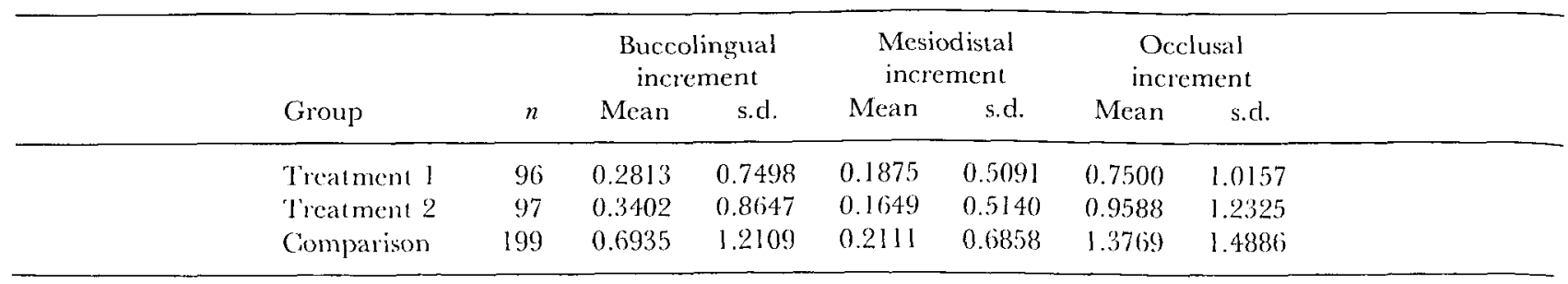

Table 4. Five-year DMFS increnent by surface type in sixth grade children, Ypsilanti, Michigan $1973-1978$

\begin{tabular}{|c|c|c|c|c|c|c|c|}
\hline Group & $n$ & Mean & s.d. & Mean & s.d. & Mean & s.cl. \\
\hline Treatment 1 & 78 & 0.1795 & 1.4392 & 0.7821 & 1.8632 & 0.8077 & 1.3198 \\
\hline Treatment 2 & 62 & 0.5645 & 1.2883 & 1.0323 & 1.8374 & 1.6613 & 1.8900 \\
\hline Comparison & 130 & 0.6935 & 1.2109 & $1.523 \mathrm{~J}$ & 2.8725 & 2.2846 & 2.2661 \\
\hline
\end{tabular}


clusal surface reductions followed the same pattern with the lowest increments for those children who continued to receive the complete preventive treatment program. These caries reductions are in addition to the benefits of water fluoridation.

\section{DISCUSSION}

The success of the program in regard to caries reductions is interesting in light of the fact that dillicultics occurred which could have biased the results in a negative direction. For example, during the study, several treatment group children were seen by local practitioners who placed restorations in many teeth which had received sealant. 'This community also became eligible for dental benefits through the auto union's insurance plans allowing scveral study children to be treated by private dentists. These factors would diminish the actual caries reductions determined for the study children. During the 4 th and 5 th year of the project, the format of the groups allowed for interesting comparisons to be made demonstrating that caries preventive procedures must be continuous for maximum bencfit to be gained. The group that received all of the procedures for 3 years and then nothing for 2 years had a drop ofl in benelit as compared to the group that received all of the procedures for 5 years.

The results showed that treatment group I received the maximum benelit from the program in contrast to group 2 which had treatment discontinued afice 3 years. The result ing 2 years of not participating in the preventive program is reflected in higher increments of caries. This study has provided signilicant information 10 indicate that a preventive program should be continuous and not just limited to a few select years. Caries reductions could not be sustained in the group that had received the program for 3 years and then not continued. For children who continued in group 1 which received the entire program lor 5 years, there was a consistent and sustained reduction in dental caries in addition to the benelits of water lluoridation. Preventive programs therefore cannot be thought of as limited or preferential in terms of the children they serve. The programs should be well planned to consider the effects of possible termination of treatment and what measures would be necessary to insure continued caries reductions. For this study, a comprehensive school-based preventive program has been able to demonstrate that for a specilic child population dental caries could be essentially prevented. The program was well accepted by parents and children, provided quality care at a reasonable cost and, most importantly, reduced dental disease.

detinureded sment - This study was supported by Grant No. NiHNIDR-72-2410 fiom the National Institule for Dental Rescauch, National Institutes of Health, Bethesda, Maryland.

\section{REFERENCES}

1. Baskswis, R. A.: Oral hygiene procedures and pit and fissure sealants. In: BuRT, B. A. (ed.): The velatize fficiency of methods of caries prevention in dental public heallh. Procecdings of a workshop at The University of Michigan, June 5-8, 1978. Ann Arbor, University Michigan, School Public Heatth 1979; pp. 123-151.

2. Backsma, R. A., GRMrs, R. C. \& BHAT, M.: A combined approach to preventing dental caries in school children: caries reductions after one year. 7. Am. Dent. Assoc. 1976 : 93: 1014-1019.

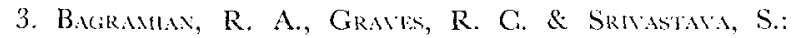
Scalant effectiveness for children receiving a combination of preventive methods in a lluoridated community: two year results. 7. Dent. Res. 1977: 56: 1511-1519.

4. Bagkanax, R. A., Gralis, R. C. \& Bhat, M.: Acombined approach to preventing dental caries in school children: caries reduction atter 3 years. Communty Dent. Oral Epidemiol. 1978: 6: 166-171.

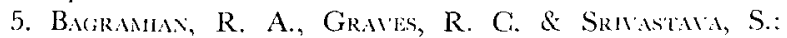
Pattern of scalant retention in children receiving a combination of preventive methods -3 year results. $7 . \mathrm{Am}$. Dent. Assoc. 1979: 98: 46-50.

6. Davils, G. N.: Cost and benefit of fluoride in the prewention of dental caries. World Health Organization, Geneva 1974.

7. Hokowty, H. S. \& Hamit, S. B.: The current status of topically applied fluorides in preventive dentistry. In: Thoms, E. N. (ed.): Fluovides and dental caries. 2nd ed. Springfield, II, 1975; pp. 46-80.

8. Jokman, W. A. et alii: The Askov dental demonstration: A.D.A. ten year study of a community dental health program; 1948-1958: Final report. Vortheest Dent. 1959: 38: 445 .

9. RIP $i$, I. W.: The current status of occlusal sealants. $f$. Prev. Den. 1976: 3: 6-14.

10. Watroman, G. E.: The Richmond-Woonsocket studies on dental care services for school children. 7. Am. Dent. Assoc. 1956: 52: 676 (only).

11. Yousc, M. A. C.: Dental health education. Int. Wealth Siche. 1970: 8: 2-26.

12. American Dental Association: Council on Dental Research and Council on Dental Therapeutics: Principles for the dinical lesting of cariostatic agents. ADA, Chicago 1972. 
This document is a scanned copy of a printed document. No warranty is given about the accuracy of the copy. Users should refer to the original published version of the material. 